\title{
Chemotherapy-induced nausea and vomiting: exploring patients' subjective experience
}

\author{
This article was published in the following Dove Press journal: \\ Journal of Multidisciplinary Healthcare \\ 4 April 2016 \\ Number of times this article has been viewed
}

\author{
Noor Salihah' \\ Nik Mazlan² \\ Pei Lin Lua ${ }^{3}$ \\ 'Faculty of Health Sciences, Universiti \\ Sultan Zainal Abidin, Kampus Gong \\ Badak, Terengganu, ${ }^{2}$ Kulliyyah of \\ Allied Health Sciences, International \\ Islamic University Malaysia, Pahang \\ ${ }^{3}$ Community Health Research Cluster, \\ Faculty of Health Sciences, Universiti \\ Sultan Zainal Abidin, Terengganu, \\ Malaysia
}

Background: This study aimed to explore the subjective experience of nausea and vomiting during chemotherapy treatment among breast cancer patients and the impacts on their daily lives.

Methods: A qualitative descriptive study was conducted in breast cancer patients who received chemotherapy and had experienced nausea and/or vomiting. Semi-structured interviews were conducted and analyzed using content analysis based on Giorgi's method.

Results: Of 15 patients who participated, 13 were included in the final analysis (median age $=46$ years, interquartile range $[\mathrm{IQR}]=6.0$; all were Malays). Vomiting was readily expressed as the "act of throwing up", but nausea was a symptom that was difficult to describe. Further exploration found great individual variation in patterns, intensity, and impact of these chemotherapy-induced nausea and vomiting (CINV) symptoms. While not all patients expressed CINV as bothersome, most patients described the symptom as quite distressing. CINV was reported to affect many aspects of patients' lives particularly eating, physical, emotional, and social functioning, but the degree of impacts was unique to each patient. One of the important themes that emerged was the increase in worship practices and "faith in God" among Malay Muslim patients when dealing with these adverse effects.

Conclusion: CINV continues to be a problem that adversely affects the daily lives of patients, hence requiring better understandings from the health care professionals on patients' needs and concerns when experiencing this symptom.

Keywords: antineoplastic agents, breast neoplasms, nausea, vomiting

\section{Introduction}

In cancer care, research has often focused on nausea and vomiting problems, mainly on the frequency and management of these symptoms. Significant developments in anti-emetic therapy with the introduction of highly effective $5 \mathrm{HT}_{3}$ receptor antagonist have improved the control of emetic episode. Ironically, nausea and vomiting are still cited by patients as the most distressing symptoms ${ }^{1,2}$ and are associated with negative effects on daily life including effects on food intake, weight loss, effects on social interactions, dehydration, difficulty with sleeping, and anxiety.,

A recent survey conducted in six Asia-Pacific countries involving 598 cancer patients revealed the apparent disconnect between clinicians' outcome expectations and patients' actual experience. ${ }^{5}$ Physicians tended to underestimate the nausea rate, particularly in the delayed phase after moderately emetogenic chemotherapy, but overestimated emesis incidence. The recognition and treatment of nausea are complicated by the fact that it can only be measured subjectively by the patient rather than objectively by the clinical staff, thus warranting more attention on effective communication than perhaps it
Community Health Research Cluster, Faculty of Health Sciences, Universiti Sultan Zainal Abidin, Kampus Gong Badak, 21300 Kuala Nerus, Terengganu, Malaysia $\mathrm{Tel}+6096688520$

Fax +6096687896

Email peilinlua@unisza.edu.my (c) (i) 2016 Salihah et al. This work is published and licensed by Dove Medical Press Limited. The full terms of this license are available at https://www.dovepress.com/terms. cc. you hereby accept the Terms. Non-commercial uses of the work are permitted without any further permission from Dove Medical Press Limited, provided the work is properly attributed. For

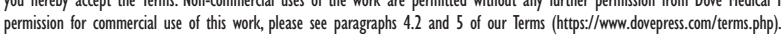


has received previously. ${ }^{3}$ Despite the discrepancy, little work has been directed to explore patients' personal experiences on nausea and vomiting for clinicians to understand these symptoms more clearly. Worsening this condition, patients tend to be at home and away from the oncology clinical environment when the symptoms are at their worst, making it hard for the health care professionals to predict what will happen to patients and what patients actually experience. As such, the aim of this study was to explore subjective patient experiences related to nausea and vomiting during their chemotherapy treatment and the impacts of these symptoms on their daily lives.

\section{Materials and methods}

\section{Study design and sample selection}

A qualitative descriptive study was conducted in an oncology outpatient clinic of Hospital Sultanah Nur Zahirah, Kuala Terengganu, Malaysia. This study was conducted to obtain in-depth descriptive data on patient experiences related to chemotherapy-induced nausea and vomiting (CINV) symptoms and their impact on patients' daily life. Patients were chosen based on purposive sampling and saturation principles using the following criteria: 1) age 18 years and above, 2) diagnosis of breast cancer at any stage, 3 ) received chemotherapy treatment and had experienced nausea and/or vomiting of any severity, 4) ability to communicate in Malay or English, and 5) written informed consent to participate in the study. Patients who were diagnosed with other malignancies or undergoing concurrent radiotherapy were excluded. Permission to conduct this study was obtained from Malaysia Ministry of Health's Research and Ethics Committee.

\section{Data collection procedure}

Eligible patients were verbally invited to participate in the study, and written consent was obtained from those who agreed to join. Baseline demographic and disease characteristics were collected from patient medical records, including age, cancer diagnosis, and treatment information. Patients who provided consent were interviewed about their nausea and vomiting experience related to chemotherapy. All interviews were conducted by the researcher face-to-face on one of the patients' follow-up visits for their chemotherapy treatment. Patients were interviewed after they had received at least one cycle of chemotherapy. The interviews were conducted in a room at the hospital, at a time convenient for the patients, and lasted for $\sim 30-40$ minutes depending on the depth of the data gathered in the interview. All the interviews were tape-recorded with the patients' permission and were transcribed verbatim. Data collection ended when no new information was obtained from the interviews, ie, data saturation had been achieved. Since this qualitative study generally focused on a homogeneous patient population, data saturation was estimated to be achieved with a minimum of ten individual interviews. ${ }^{6}$

\section{Study tool}

A semi-structured interview guide consisting of six questions was used as the study tool (Figure 1). The interview guide was developed after an extensive literature review ${ }^{3,4,7,8}$ to create and identify the questions with specific probes while keeping the questions as open as possible to give patients maximum opportunity to express their views.

\section{Data analysis}

Content analysis was used to analyze the interview data, using a system of open coding where data were analyzed, compared, and categorized. This qualitative content was based on Giorgi's method, ${ }^{9}$ aiming to identify the central theme from the content rather than to count the phases or words that appeared frequently. The six questions used as the interview guide became themes around which the data were later organized, and the responses related to each one of these themes were grouped together. Within each broad theme, codes and sub-codes were developed. To ensure data validity, the coding reports were also read independently by two other researchers who have had experience with qualitative research. The codes were compared, whereby the similarities and differences in understanding and interpretation were discussed. ${ }^{10}$ Qualitative data were analyzed using the qualitative package NVivo (Version 8; QSR International, Melbourne, Australia), while demographic characteristics were assessed using descriptive statistics (SPSS Version 16; SPSS Inc., Chicago, IL, USA).

\section{Results}

\section{Patient characteristics}

Of the 20 patients who were approached to participate in this study, 15 accepted our invitation; however, only 13 were included in the final analysis because two were afflicted by low data quality due to the lack of patients' response. Reasons for declining included "not interested" or "too tired". Characteristics of the patients are summarized in Table 1. The median age of the participants was 46 years (interquartile range $[\mathrm{IQR}]=6.0)$, and all were Malays $(100 \%)$. Majority of the patients were newly diagnosed ( $\leq 1$ year after diagnosis) 
1. Define nausea and vomiting using patients' own words.

2. Describe individual experience on CINV in terms of:
a. Severity
b. Duration
c. Previous history of nausea and vomiting

3. Are there any other symptoms experienced together with CINV?

a. Nutritional problems (eg, mucositis, loss of appetite, smell/taste changes, regurgitation, bloating, burping, foods hedonic)

b. Physical and psychological symptoms (eg, fatigue, distress)

c. Others (eg, sore throat, sweating, sleep disturbance, flu-like symptoms, feeling hot and cold, intolerance of smell)

4. How and what they ate when they were nauseated?
a. Meal frequency
b. Types and amount of food/ drinks (texture, smell, craving for certain foods)
c. Foods avoided
d. Any nutritional supplements

5. How much CINV has affected their lives in terms of:

a. Eating pattern (pre-chemotherapy cycle, during and post-CINV period)

b. Social life (ie, being with family and friends)

c. Emotional well-being (eg, distress)

6. How they manage the symptoms?
a. Adherence to anti-emetic prescriptions
b. Use of complementary therapies (eg, aromatherapy, herbs)
c. Dietary strategies

Figure I Interview guidelines.

Abbreviation: CINV, chemotherapy-induced nausea and vomiting.

(84.6\%) and were at early stage (stage I and II) of breast cancer diagnosis $(53.8 \%)$. The median body mass index (BMI) was $25.6 \mathrm{~kg} / \mathrm{m}^{2}(\mathrm{IQR}=7.0) ; 61.5 \%$ were overweight or obese and $38.5 \%$ were normal. Approximately $80 \%$ of patients had received three cycles of chemotherapy by the time of their interviews. The chemotherapy drugs administered were FEC (5-fluorouracil, epirubicin, cyclophosphamide) and TAC (docetaxel, doxorubicin, and cyclophosphamide) for highly emetogenic regimen or docetaxel $(\mathrm{T})$ for lower emetogenic chemotherapy protocols. ${ }^{11}$

Table I Characteristics of patients $(n=\mid 3)$

\begin{tabular}{|c|c|c|c|c|c|c|c|c|}
\hline Number & Patients' ID & $\begin{array}{l}\text { Age } \\
\text { (years) }\end{array}$ & $\begin{array}{l}\text { Marital } \\
\text { status }\end{array}$ & $\begin{array}{l}\text { Employment } \\
\text { status }\end{array}$ & $\begin{array}{l}\text { Breast } \\
\text { cancer } \\
\text { stages }\end{array}$ & $\begin{array}{l}\text { Duration since } \\
\text { cancer diagnosis } \\
\text { (months) }\end{array}$ & $\begin{array}{l}\text { Chemotherapy } \\
\text { cycle }\end{array}$ & $\begin{array}{l}\text { Chemotherapeutic } \\
\text { agents }\end{array}$ \\
\hline I & $P \mid 8$ & 44 & Married & Sales person & II & 10 & Third & TAC \\
\hline 2 & P 21 & 48 & Divorced & Businesswoman & III & 6 & Second & FEC \\
\hline 3 & P 22 & 46 & Married & Businesswoman & II & 24 & Third & FEC \\
\hline 4 & P 23 & 51 & Married & Retiree & II & 6 & Third & FEC \\
\hline 5 & P 24 & 47 & Married & Housewife & III & 16 & Fourth & $\mathrm{T}$ \\
\hline 6 & P 25 & 42 & Married & Housewife & II & 6 & Third & FEC \\
\hline 7 & P 26 & 47 & Married & Public servant & II & 3 & Fifth & $\mathrm{T}$ \\
\hline 8 & P 27 & 66 & Divorced & Public servant & II & 4 & Fourth & FEC \\
\hline 9 & P 42 & 55 & Married & Housewife & IV & 4 & Fourth & $\mathrm{T}$ \\
\hline 10 & P 43 & 36 & Married & Public servant & III & 3 & Second & FEC \\
\hline 11 & P 47 & 44 & Married & Public servant & III & 3 & Second & TAC \\
\hline 12 & P 48 & 44 & Married & Public servant & II & 4 & Fourth & FEC \\
\hline 13 & P 49 & 45 & Married & Housewife & III & 6 & Fourth & FEC \\
\hline
\end{tabular}

Abbreviations: TAC, docetaxel, doxorubicin, and cyclophosphamide; FEC, 5-fluorouracil, epirubicin, cyclophosphamide; T, docetaxel; ID, identification. 


\section{Theme I: Patients' definition of nausea and vomiting}

Nausea was difficult to describe according to patients' comprehension. Patients mostly described the nausea symptoms by pointing out the ache or unsettled feeling sensations localized to the stomach and also in the throat. They also described it as feeling the need to vomit.

[...] after chemotherapy, on the way home, I felt my stomach contents were "shaken up". When I arrived at home, I felt nauseous in the throat [...] [P 42]

Nausea $[\ldots]$ ermm $[\ldots]$ the feeling comes when I tried to vomit, but failed, yet I felt aches all over my stomach and waist [...] [P 23]

By contrast, vomiting was more readily expressed by the patients. Vomiting was usually described as the act of throwing up of the stomach content. Patients described the act in their own words such as "the food was coming out" or "when something came out".

[...] what we ate, all was coming out back [...] [P 48]

[...] after the chemotherapy drug was administered, I started to vomit, something came out (from stomach). [P 22]

\section{Theme 2: Description of experiences with CINV}

Patients experienced both acute and delayed symptoms with a wide range of severity. Some of them also expressed how debilitating it could be to feel nauseous without actually vomiting. Nausea started during the first day of chemotherapy; for some, it would markedly worsen after they got home, during the following night or a few days after treatment. The delayed symptoms could last from 2 days up to 1 week.

After going back from chemotherapy, I continuously felt nauseous until midnight, but did not vomit. I couldn't even lie down to sleep all-night [...] (because of) nausea. [P 22]

$[\ldots]$ if I could rate the severity, it was $[\ldots]$ erm $[\ldots] 5$ or 6 over 10, for a week, (I felt nauseous). [P27]

As for vomiting, some patients considered it as a mild symptom. They even felt relief after vomiting. Five patients did not experience emesis; they only had nausea during their previous chemotherapy cycle. However, other patients found their vomiting experience an awful event. For instance, a woman experiencing severe emesis commented:

[...] it was severe, when vomiting, muscles of the stomach were highly pressured, it was worst. Although there were nothing left (stomach contents), I kept throwing-up. [P 42]

\section{Theme 3: Concurrent and associated symptoms}

Throughout the chemotherapy cycle, a range of symptoms linked to CINV was reported by the patients. Based on symptoms categorization by Molassiotis et al, ${ }^{8}$ the symptoms were grouped into concurrent (those that were not consistently present along with CINV) and associated symptoms (those symptoms that patients clearly described as temporally occurring in conjunction with CINV). Concurrent symptoms included sleep disturbance $(n=4)$, bloating $(n=2)$, fatigue $(n=7)$, sore throat $(n=2)$, flu-like symptoms $(n=3)$, and feeling hot $(n=4)$. Oral symptoms such as mucositis and swollen gums were also frequently present along with CINV. Associated symptoms that occurred together with nausea included burping $(n=1)$, intolerance of smells $(n=2)$, taste disturbance $(n=3)$, loss of appetite $(n=7)$, and vomiting $(n=5)$. Several symptoms including loss of appetite, fatigue, nausea, and vomiting often occurred simultaneously, suggesting possible symptom cluster.

I eat less because of nausea, I felt terribly tired! [...] [P 25]

I didn't feel like eating anything except for porridge. It was like being pregnant, I can’t look at the most foods, I felt nauseous [...] [P 42]

\section{Theme 4: Impacts of CINV on eating pattern}

The days of nausea and vomiting had clearly imposed negative effects on their food and fluid intake. Nutritional intake was reported to decrease significantly during chemotherapy. Despite attempts to force themselves to eat something, they could not consume much as it was even hard to just finish a simple meal like bread or biscuits. This condition would be exacerbated by the presence of persistent vomiting that occurred in some patients, thus further limiting patients' food consumption.

[...] it was three to four days, I kept vomiting. After vomiting, I felt hungry, then I ate, but again, I vomited [...] I couldn't even eat rice, just drank a lot of water, the same with desserts (traditional cakes), I also couldn't eat them. I was hardly eating within that one week period (postchemotherapy). [P 42]

Subjective smell and taste changes were also reported by patients to occur just after chemotherapy administration, but faded after 2 or 3 weeks. Changes in taste perception associated with a metallic taste and spicy foods had altered the taste of food. Foods could be described as really bland, terribly spicy, too sweet, bitter, and had metallic taste. Even 
the smell of food could sometimes be a turn-off for having meals. Smooth, soft food was sometimes preferred, and soups were often better tolerated.

Only a few tried nutritional supplement since they were worried, maybe, that it would interfere with their ongoing chemotherapy treatment, avoiding any possible side-effects. The following quotes illustrate some of the patient responses on question of whether or not they had taken any nutritional supplements.

[...] No. All that I ate were medications from hospital.

I didn't buy any medications or supplements from outside. [P 43]

[...] not yet, may be after completing this (chemotherapy) treatment [...] [P 47]

Previously, I had taken a fruit-extract supplement, but I stop eating it upon starting chemotherapy treatment. [P 18]

Theme 5: Impacts of CINV on daily life

Majority of the patients reported that they were upset and distressed by these CINV symptoms since they could not perform their normal activities. However, they mentioned that they had continuously received ample support from their family members during this tough period. However, for those with only mild nausea, they noted that nausea had neither bothered them nor affected their life in any way.

After chemotherapy, I felt sick, I couldn't afford to move around much, I couldn't do all the housework, even my mum helped me to cook. After 12 day "feeling sick" (nauseous), then I could start to move around or do the housework again. [P 18]

I get emotional and aggravated sometimes, but these feeling wouldn't last long. Because my family gave full support, thus I felt less distress. [P 49]

Right now, I couldn't cook anymore, but if I wanted to have a malted drink ("milo"), my husband would help me to serve it. My mum would also help me to cook, she cook porridge ("bubur lambuk") for me. [P 43]

Since all patients were Muslims, there was an increase in their worshipping needs after receiving chemotherapy, which was plagued with various debilitating side effects. They tried to relax and deal with the symptoms by devoting more time to worship in accordance with the Islamic faith (eg, praying to God, reciting the Quran, and counting beads). The belief that all came from God and it was their fate to develop breast cancer disease and deal with the treatment side effects has also helped them to be more positive in dealing with the hardships.

[...] sometimes, I feel distressed, but [...] not that bad. I've always prayed to God for a peace of mind to go through this [...] furthermore, I've got strong support from my husband, children, and siblings. Every weekend, they went home (to visit me) [...] [P 43]

\section{Theme 6: Controlling nausea and vomiting}

Anti-emetic medication is still the most common strategy for managing nausea. The use of oral anti-emetic was reported by $76.9 \%$ of patients. However, the experiences with anti-emetic treatment were perceived differently by the patients. Majority (61.5\%) expressed their satisfaction with this pharmacological therapy as being somewhat useful. While anti-emetics were helpful for many of the patients, some patients stated that they were not often fully effective. This comment was particularly related to patients who experienced greater severity of nausea.

I've taken it (anti-emetics). I didn't vomit but still, I had nausea. [P 26]

Although I've taken the medication, I still vomited. [P 27]

Participants also reported the frequent use of several dietary strategies as a non-pharmacological self-care approach. They tried to force themselves to eat, modified their diets, avoided fried or fatty foods, increased fruit and fluid intakes, consumed small meals more frequently, and avoided eating when nauseous in order to cope with CINV.

On the first day post-chemotherapy, I couldn't eat, I just drank[...] If I couldn't eat rice, I ate porridge and sometimes this (condition) lasted for two days [...] [P 43]

I ate rice as usual, but added more soup [...] I drank more water and ate more fruits. [P 18]

Apart from non-pharmacological self-care approach, selfmanagement approaches were also often used by the patients. Some patients were able to cope with the CINV symptoms by using distraction techniques and rest such as laying down, napping, or "taking it easy". Two patients mentioned using aromatic medicated oil to treat their nausea.

\section{Discussion}

The qualitative data obtained from this study have provided deeper insights on patients' subjective experience of CINV and how these symptoms have affected their daily life. The exploration of patients' experience on nausea and vomiting during cytotoxic chemotherapy found great individual 
variation in patterns, intensity, and impact of these symptoms. While not all patients expressed CINV as bothersome, most patients described the symptom as quite distressing. Challenges in communicating about CINV (particularly nausea) became evident through this study as patients lacked words to describe this symptom. Similar findings have also been reported by Molassiotis et al, ${ }^{8}$ indicating that nausea was not only a difficult symptom to describe, but also a complex symptom with which patients struggled to cope by themselves. As nausea is subjective and unobservable, effective communication between health care providers and patients is therefore essential for its effective management.

Close connections between CINV and symptoms such as loss of appetite and fatigue were noted in this explorative study, thus demanding further investigations. These findings are again in line with Molassiotis et $\mathrm{al}^{8}$ who reported associations between CINV and such manifestations with several others (ie, taste disturbance and intolerance of smell) in cancer patients receiving chemotherapy. An earlier qualitative study conducted in 220 elderly patients with lung cancer also discovered that fatigue, nausea, appetite loss, weight loss, taste changes, and vomiting actually formed a cluster of symptoms. ${ }^{12}$ This is one indication that it may be important for future research to investigate such clusters rather than individual symptoms by further clarifying particular symptom clusters and their synergistic effects on patient morbidity.

In addition, the experiences of nausea and vomiting during chemotherapy treatment have a profound effect on patients' daily lives. Depending on their severity and duration, different impacts on food intake, social interaction, sleeping patterns, and fatigue have been discussed by the patients, confirming that CINV remains a problem. Consistent with prior investigations, ${ }^{3,4,8}$ experiencing CINV, especially for delayed symptoms, had made patients restrict eating and feel exhausted for a long period after chemotherapy, which in turn could potentially prolong patients' recovery between treatment cycles. The importance of CINV in limiting patients' dietary intake is expected. A multitude of nutrition impact symptoms that were present along with CINV (eg, mucositis, loss of appetite, intolerance of smell, and taste disturbance) further exacerbated the degree of symptom interference with eating. This was a major concern because not being able to eat properly after and between cycles would undoubtedly expose patients to the risk of malnutrition. ${ }^{13}$

Nevertheless, patients' descriptions revealed that they had to reframe their eating behaviors using a variety of dietary strategies upon experiencing this symptom. Other useful self-management strategies used by patients included distraction techniques and application of aromatic medicated oil. There is no doubt that anti-emetic treatment using $5 \mathrm{HT}_{3}$ receptor antagonists is currently the best treatment in controlling CINV symptoms. However, these conventional anti-emetics are more successful in preventing emesis than in preventing nausea. ${ }^{14}$ As such, patients may also benefit from non-pharmacological approaches such as acupressure, electro-acupuncture, ginger, prognostic muscle relaxation, ${ }^{15}$ or self-management strategies that have been mentioned before. Limited research has been conducted assessing the effectiveness of these treatment approaches, which thus could potentially serve as a critical area of self-management research in the near future.

Besides, in this study, patients also revealed that they were unable to fulfill their domestic roles during the presence of CINV symptoms. Similarly, Cohen et $\mathrm{al}^{2}$ and Hilarius et al ${ }^{16}$ found that CINV significantly interfered with patients' daily functioning. In our Malay society, women are generally the primary caregivers, who carry the responsibility of housework and the general care of their children and husband. The family dynamics could be adversely affected when the health of women deteriorates. However, family members continuously provide unconditional support, thus helping patients fulfill their normal duties whilst experiencing this chemotherapy side effect. This is vital because social support and assistance provided to women with breast cancer have helped to improve their coping behaviors, strengthening them, decreasing their distress, and consequently increasing their quality of life. ${ }^{17}$

One of the important findings in our study was the increase in worship practices and "faith in God" among Malay Muslim breast cancer patients when dealing with chemotherapy adverse effects, including CINV events. Numerous studies also previously demonstrated that spirituality and religious activities were associated with better coping and psychological well-being among breast cancer patients. ${ }^{18-20}$ The identification of such experiences may provide health care professionals with an opportunity to gain better insight from a designated community, which would then facilitate the designing of appropriate culturally sensitive interventions for different sociocultural backgrounds.

Nonetheless, our study was confined to several limitations. Firstly, the data were gathered only from women with breast cancer who were receiving chemotherapy in the oncology outpatient clinic of a government hospital. The findings were specifically related to this particular setting but may still be applicable into similar domains of care. Secondly, a potential for bias did exist since this qualitative 
interview-based study tended to attract homogeneous groups of patients and only those who wished to speak about it. Despite these limitations, the result should be seen as a contribution to an ongoing effort to fill the gap in the literature and to comprehend patients' experience on CINV, of which qualitative investigations are still scarce.

\section{Conclusion}

In summary, this preliminary qualitative study has provided a current perspective of breast cancer patients regarding their subjective experiences of nausea and vomiting during chemotherapy. Communicating about CINV, particularly nausea, was a challenge to this group of patients, but the individual dimensions of CINV symptoms burden were obvious. CINV has affected many aspects of patients' lives, especially those related to eating, physical, emotional, and social functioning, but the degree of impacts was unique to each patient. The rich description of CINV experiences gained from this study is expected to help health care professionals to better understand patients' needs and concerns when experiencing this symptom. Considering the complexity of these CINV symptoms, specific assessment and innovative approaches for its subsequent management are highly needed.

\section{Acknowledgments}

The authors are grateful to the Director General of Health, staff, respondents, and patients of Hospital Sultanah Nur Zahirah as well as those who helped facilitate the process of this study. Financial support for this project was provided by Universiti Sultan Zainal Abidin (grant number: UniSZA.B/2/ KP9/628).

\section{Disclosure}

The authors report no conflicts of interest in this work.

\section{References}

1. Grunberg SM, Deuson RR, Mavros P, et al. Incidence of chemotherapyinduced nausea and emesis after modern antiemetics. Cancer. 2004;100(10):2261-2268.

2. Cohen L, de Moor CA, Eisenberg P, Ming EE, Hu H. Chemotherapyinduced nausea and vomiting: incidence and impact on patient quality of life at community oncology settings. Support Care Cancer. 2007; 15(5):497-503.

Journal of Multidisciplinary Healthcare

\section{Publish your work in this journal}

The Journal of Multidisciplinary Healthcare is an international, peerreviewed open-access journal that aims to represent and publish research in healthcare areas delivered by practitioners of different disciplines. This includes studies and reviews conducted by multidisciplinary teams as well as research which evaluates the results or conduct of such teams or
3. Foubert J, Vaessen G. Nausea: the neglected symptom? Eur J Oncol Nurs. 2005;9(1):21-32.

4. Bergkvist K, Wengström Y. Symptom experiences during chemotherapy treatment--with focus on nausea and vomiting. Eur J Oncol Nurs. 2006;10(1):21-29.

5. Hsieh RK, Chan A, Kim HK, et al. Baseline patient characteristics, incidence of CINV, and physician perception of CINV incidence following moderately and highly emetogenic chemotherapy in Asia Pacific countries. Support Care Cancer. 2015;23(1):263-272.

6. Kerr C, Nixon A, Wild D. Assessing and demonstrating data saturation in qualitative inquiry supporting patient-reported outcomes research. Expert Rev Pharmacoecon Outcomes Res. 2010;10(3):269-281.

7. Cebeci F, Yangın HB, Tekeli A. Life experiences of women with breast cancer in south western Turkey: a qualitative study. Eur J Oncol Nurs. 2012;16(4):406-412.

8. Molassiotis A, Stricker CT, Eaby B, Velders L, Coventry PA. Understanding the concept of chemotherapy-related nausea: the patient experience. Eur J Cancer Care (Engl). 2008;17(5):444-453.

9. Polit DF, Beck CT. Nursing Research: Principles and Methods. Philadelphia, PA: Lippincott Williams and Wilkins; 2004.

10. Graneheim UH, Lundman B. Qualitative content analysis in nursing research: concepts, procedures and measures to achieve trustworthiness. Nurse Educ Today. 2004;24(2):105-112.

11. Basch E, Prestrud AA, Hesketh P, et al. Antiemetics: American Society of Clinical Oncology clinical practice guideline update. J Clin Oncol. 2011;29(31):4189-4198.

12. Gift AG, Jablonski A, Stommel M, Given CW. Symptom clusters in elderly patients with lung cancer. Oncol Nurs Forum. 2004; 31(2):202-212.

13. Capra S, Ferguson M, Ried K. Cancer: impact of nutrition intervention outcome-nutrition issues for patients. Nutrition. 2001;17:769-772.

14. Roila F, Herrstedt J, Aapro M, et al. Guideline update for MASCC and ESMO in the prevention of chemotherapy- and radiotherapy-induced nausea and vomiting: results of the Perugia consensus conference. Ann Oncol. 2010;21(suppl_5):v232-v243.

15. Greenlee H, Balneaves LG, Carlson LE, et al. Clinical practice guidelines on the use of integrative therapies as supportive care in patients treated for breast cancer. J Natl Cancer Inst Monogr. 2014;50:346-358.

16. Hilarius DL, Kloeg PH, van der Wall E, van den Heuvel JJG, Gundy CM, Aaronson NK. Chemotherapy-induced nausea and vomiting in daily clinical practice: a community hospital-based study. Support Care Cancer. 2012;20:107-117.

17. Gurm BK, Stephen J, MacKenzie G, Doll R, Barroetavena M, Cadell S. Understanding Canadian Punjabi-speaking South Asian women's experience of breast cancer: a qualitative study. Int J Nurs Stud. 2008;45(2):266-276.

18. Bussing A, Abu-Hassan WM, Matthiessen PF, Ostermann T. Spirituality, religiosity, and dealing with illness in Arabic and German patients. Saudi Med J. 2007;28(6):933-942.

19. Choumanova I, Wanat S, Barrett R, Koopman C. Religion and spirituality in coping with breast cancer: perspectives of Chilean women. Breast J. 2006;12(4):349-352.

20. Harandy TF, Ghofranipour F, Montazeri A, et al. Muslim breast cancer survivor spirituality: coping strategy or health seeking behavior hindrance? Health Care Women Int. 2010;31(1):88-98.

\section{Dovepress}

healthcare processes in general. The journal covers a wide range of areas and welcomes submissions from practitioners at all levels, from all over the world. The manuscript management system is completely online and includes a very quick and fair peer-review system. Visit http://www.dovepress.com/testimonials.php to read real quotes from published authors. 